\title{
Reshaping Our World: The Opportunities and Challenges Associated with Climate Change-Induced Migration
}

\author{
Elizabeth W. Carper ${ }^{1}$ \\ ${ }^{1}$ University of St Andrews, St Andrews, Scotland, USA \\ Correspondence: Elizabeth W. Carper, University of St Andrews, St Andrews, Scotland, USA. E-mail: \\ Elizabethcarper17@gmail.com
}

Received: March 15, 2019

Accepted: April 23, 2019 Online Published: May 30, 2019

doi:10.5539/jsd.v12n3p175

URL: https://doi.org/10.5539/jsd.v12n3p175

\begin{abstract}
Climate change-induced migration is an emerging issue that poses significant humanitarian, economic, and political consequences if not addressed on the international stage. Yet, its interdisciplinary nature, while cementing it as a greater sustainable development concern, confounds policymaking. Disregarding the implications of climate change, including but not limited to resource insecurity and overpopulation leading to instability and conflict, only exacerbates the probability of climate change-induced migration becoming a humanitarian disaster. The most prominent hindrance to the development of such a policy is the lack of a universal approach for recognizing climate refugees. Recognition poses opportunities for globalization, however it also poses challenges stemming from negative perceptions of migrants. Nonetheless, this synthesis of existing literature illustrates that collaborative efforts for the international recognition of climate migrants - as well as their capacities for adaptation and resilience - is crucial to create opportunities for sustainable development.

Following the conceptual context regarding climate science and terminology, it is the aim of this review to analyze the adaptive capacity of affected populations and how migration is becoming a form of adaptation itself. Second, in an increasingly-isolationist world, there is a heightened fear of refugees crossing international borders. It is crucial to discuss the securitization of climate change and its classification as a non-traditional security threat. It is apparent that while most climate change-induced migration will be internal, it remains imperative to develop effective international policy. In the subsequent discussion of potential policy avenues, it is argued that given the appropriate opportunities to engage in their new communities, refugees are capable of significant contribution, despite their misperception as dependents. By integrating this information into one comprehensive document, policymakers may acknowledge the importance of recognizing and extending protections to climate migrants.
\end{abstract}

\section{Introduction}

Evidence of anthropogenic climate change is largely accepted in the wider scientific community, however strategies as to how to address it and its implications differ. Climate change is a complicated and multifaceted phenomenon, much like the greater enterprise of sustainable development, that requires an interdisciplinary approach to address its significant and wide-ranging environmental and socio-economic impacts. While the current discourse surrounding it predominantly involves reducing greenhouse gases, the majority of the social implications are largely understated in the international political realm. Human migration caused by climate change must be addressed in the geopolitical climate framework. The recognition of climate change-induced migration as a complex issue indicates that there is a need for a comprehensive document that collects and analyzes the growing body of literature on this topic. Contextualizing and synthesizing current scholarship will be necessary to determine best-practices in approaching the greater issue of climate change-induced migration. Through the examination of existing literature surrounding the geopolitical conversation on climate-induced migration, it is apparent that the first crucial step towards effective policymaking is to develop a framework to recognizing climate refugees, that addresses the associated challenges as well as the opportunities.

This review will outline this interdisciplinary issue, analyze the relationship between migration and adaptation, and discuss the securitization of climate migration. These sections will be followed by a discussion of the existing policy frameworks that attempt to consolidate these factors, and identify opportunities for future policymaking. Due to the limited scope of this paper and the complex nature of this topic, many details including but not limited 
to concerns of health and specificities of case studies will be left out. While important, these factors are not critical to this overarching evaluation.

\section{Conceptual Context}

Before discussing the implications surrounding climate-induced migration (CIM) it is necessary to understand the basic underlying natural science of climate change as well as the diverse terminology and concepts associated with CIM. The Intergovernmental Panel on Climate Change (IPCC) report concludes it is "extremely likely" that the observed global warming is the result of the unprecedented increase in concentrations of carbon dioxide, methane, and nitrous oxides driven by economic and population growth since the Industrial era (IPCC 2014). Specifically, anthropogenic climate change will "[increase] in severity and frequency extreme weather events" in vulnerable regions (Biermann \& Boas 2008, p.10). Low-lying deltas, coastal cities, and small island states are at significant risk of inundation with only minimal sea level rise caused by atmospheric warming and glacial retreat. Droughts and food scarcity will amplify. With only minimal climate change, 700 million to 2 billion people could be displaced by these direct causes alone (Biermann \& Boas 2008). Approximately 50-60 percent of the world's population relies on Himalayan glacial meltwaters as a source of water for consumption, agriculture, and commercial purposes, and are thus at significant risk from the effects of global warming (Biermann \& Boas 2008). Marginalized communities and developing countries that have contributed the least to climate change will be the most impacted as they neither have the resources nor capacity to adapt to amplified climate change. It will ultimately be these people with very little adaptive capacity that will be faced with the difficult decision of whether to migrate or remain.

It should be noted that the IPCC report does not conclusively attribute causation of climate change to human development, however this causality is "extremely likely" with a narrow margin of error (Ayers et al 2010). Additionally, at the time of writing, the most recent IPCC report only briefly cites migration as a response to climate change (IPCC 2014). It does, however, attribute the possibility of human population displacement to increased incidence of sea level rise, intensification of storm surges, and resource scarcity, thus effectively identifying direct, easily-identifiable factors of migration. It is expected of the IPCC to remain neutral without alienating certain policy influencers by linking climate change and greater societal issues, such as instability and loss of livelihood. The purpose is to influence effective, overarching policy that reaches the largest amount of people. Thus, when developing their policy frameworks, many scholars choose to focus solely on the direct pathways because the effect channels become more complex and difficult to disentangle as indirect factors are included (Biermann \& Boas 2012). As a result, it is difficult to develop a framework for recognizing climate refugees. Biermann and Boas $(2008 ; 2010 ; 2012)$, arguably some of the most prevalent scholars on this topic, focus solely on direct causality for this reason.

Broadly, the existing literature can be split into two categories for identifying climate migrants, those that cover only direct causes - specifically displacement as a result of purely environmental stressors - and those that include both direct and indirect causes - displacement due to environmental, political, economic, and social factors amplified by climate change (Black et al 2011). It is necessary to consider both categories and contemplate all potential climate-induced drivers of migration. Black et al (2011) provide a framework that makes an argument for the inclusion of both categories and concludes that the individual decision to migrate is dependent on a combination of different but interdependent factors. Ultimately, the nature of policy interventions is dependent on which factors are utilized to identify climate migrants. Thus, this distinction is further addressed in this review's analysis.

Before developing policy, it is crucial to define what characterizes a population as climate refugees. The overarching concern evident in the literature is that there is no clear identifier of climate refugees (Ahmed 2018; Fiddian-Qasmiyah et al 2014; Zetter 2011). The debate is rooted in conflicting definitions across regions and climate impacts. No overarching definition exists because the issue of CIM cannot be generalized (Betts et al 2016). When selecting a term, the political, economic, and social ramifications must be considered. The 1951 Geneva Convention defines a refugee as anyone "fleeing, or has a well-founded fear of, persecution for reasons of race, gender, religion, nationality, membership of a particular social group or political affiliation" (Berchin et al 2017, p.147). This is the overarching definition in the traditional sense, and despite insistence from the scientific community for the inclusion of those fleeing climate impacts, this original definition of refugee remains (Biermann \& Boas 2012; Boas 2017). Additionally, despite the UN Environment Programme popularizing the term "environmental refugee" in the 1980s, the official institutions that would feasibly concern CIM, including the UN High Commissioner for Refugees and Universal Declaration on Human Rights, believe broadening the original definition would undermine protections for existing refugees (Hartmann 2010). At the time of writing, climate refugees remain legally unrecognized by the UN (Berchin et al 2017). 
Other scholars agree that the term refugee victimizes the migrants, devaluing them as humans and disregarding their resilience capacity (Herrmann 2017). Moreover, it is argued that the term "reinforces a unilateral view that environmental change is the sole cause of forced migration", when in actuality CIM is an exceedingly multifaceted issue (Farbotko \& Lazrus 2012, p.384). The utilization of refugee can shift focus away from proper climate mitigation strategies as it assumes catastrophic climate change, and the consequent mass migration, as an inevitability (Herrmann 2017). By branding climate migrants as refugees, it is argued that policymakers are ignoring the possibility that it can be prevented through climate mitigation and adaptation (White 2011). Therefore, the overall narrative of climate change is shifted from one of prevention to reaction. While there are valid arguments against the utilization of refugee, other scholars contend that the term incites a moral and legal obligation of "societal protection" from the international community that has contributed the most to climate change (Biermann \& Boas 2010, p.258).

Small Island Developing States (SIDS) are among the first to consider large-scale migration. Specifically in Tuvalu, as well as throughout the Pacific, while the citizens reject the use of refugee due to the aforementioned connotations of victimization, the Tuvalu government prefers the term as it highlights the severity of the issue and the need for global-scale mitigation (Farbotko \& Lazrus 2012). Essentially, depending on context, there are multiple implications of the term refugee, and all assume a level of disempowerment as refugees' survival is ultimately dependent on international response. In order to circumvent these connotations, other scholars have identified alternative terminology, including migrant and environmentally displaced person (Herrmann 2017). There are also limitations to each of these terms as well. The term migrant can easily construe a "level of volition" (European Commission 2013, pp.14-5). It assumes migrants migrate of their own choice and none were forcibly displaced, when in actuality those who decide to migrate as a form of adaptation do so only because adverse climate impacts exist. The term environmentally displaced person, preferred by many intergovernmental institutions, is the most recent definition and is broad enough to encompass both refugees and migrants, however it tends to absolve a sense of responsibility for the international community (Biermann \& Boas 2010). Despite the lack of recognition by the international community, it is agreed in existing scholarship that a climate change refugee is any person who "has been forced to leave their home, or their country, due to the effects of severe climate events, being forced to rebuild their lives in other places" (Berchin et al 2017, p.147).

In addition to the already complex discussion surrounding recognizing climate refugees, is the securitization of CIM in global politics. Climate change will be a security issue and a threat to economic and political stability worldwide, if not properly addressed (Boas 2017; White 2011). Climate change is framed as a non-traditional security threat —or a threat outside the conventional sense of warfare and terrorism — as it threatens the longevity of resources that support societies as well as indirectly amplifying pre-existing conditions of instability and conflict (Srikanth 2014). Any security discussion must consider preventing these security threats through migration as adaptation, and mitigating climate change wholesale to prevent mass migration (Black et al 2011).

While it is evident that there is no clear international consensus on how to identify climate refugees and specific terminology, an understanding of the broad concepts is essential when considering the complex issue that is climate-induced migration. It is beyond the scope of this paper to conclude which is the most appropriate and will thus utilize refugee and migrant interchangeably. In the following sections, these concepts will be elaborated on and applied to the greater analysis of policy discourse.

\section{Adaptation: Migration and Resilience}

Climate-induced migration is viewed separate from adaptation and mitigation as it is predominately considered a disaster, or a worst-case scenario. However, it is argued that the two should be "conceptualized together" so migration is seen as part of the solution rather than an "inherent problem" (Farbotko \& Lazrus 2012, p.384). CIM can easily be considered a method of adaptation and an opportunity, as opposed to solely a potential security threat. Migration, unlike the worst-case consequences of irreversible climate change, is not a distant issue to be left to future generations to solve. The process of mass displacement from the most vulnerable communities is already underway, centered predominantly in the South Pacific and low-lying deltaic regions where involuntary migration is a matter of survival (Byravan \& Rajan 2015). The residents of vulnerable regions are already considering their options, weighing the costs and benefits of migration or remaining behind (Mortreaux \& Barnett 2009). Regardless of whether some people choose to remain, it must be assumed that many others will choose to migrate, especially if sea levels continue to rise.

A provocative argument set forth by Mortreaux \& Barnett (2009) calls for an understanding of the "unequivocal human right" of decision-making. As impacts from climate change become more widespread, the ability to choose to remain with one's homeland diminishes. Even in SIDS, where inundation is a reality of the $21^{\text {st }}$ century, having 
the choice to remain is better than having no choice at all, and it is a choice important to many vulnerable communities (Farbotko \& Lazrus 2012). The connection of climate adaptation and human rights is one that requires further examination in research.

CIM is perceived as a worst-case scenario, and the language used to brand climate refugees in the wider policy conversation reinforce this. This unfounded perception of large-scale migration leading to a catastrophic humanitarian crisis can be circumvented more effectively through measures of global mitigation, and sustainability and resiliency strategies on the regional level (Biermann \& Boas 2008). Through the use of voluntary migration strategies, resilience can be achieved and large-scale migration can be prevented (Farbotko \& Lazrus 2012). Incentives are necessary for vulnerable communities to encourage emigration, but they must also encourage receiving communities to accept those immigrants. Such incentives will be evaluated below. New policies require more open, diplomatic immigration to provide for these voluntary climate migrants and avoid a wider refugee crisis. The connection between planned relocation as a cooperative adaptation effort is closely linked with security, and thus will be explored in the following sections.

Additionally, scrutiny of disaster risk management literature is essential when developing frameworks for planned migration. Cost-benefit and risk analyses that evaluate different scenarios of sustainable development, including investing in resilient infrastructure and determining methods of resettlement, are crucial (Tyler \& Moench 2012; Thomalla et al 2006). These frameworks would additionally require a level of behavioral economics as locals' risk perceptions can be evaluated in order to anticipate future possible migration patterns (Mortreux \& Barnett 2009). It is beneficial for future research to explore the application of behavioral economics to migratory patterns, specifically in preparation of CIM.

Small Island Developing States often endure poor adaptive capacity in terms of low economic capital, extreme resource scarcity, and high population densities. The governments of these developing countries are considering sensible options to preserve their national identities as a culture but also prolong the lifetime of their homelands by alleviating some population pressure on the islands' resiliency capacity, in strategies referred to as "migration with dignity" (Farbotko \& Lazrus 2012). Planned resettlement is the most economically, politically, and socially optimal solution (Farbotko \& Lazrus 2012; Wyett 2013). By facilitating organized resettlement, the cost of future migration will be reduced. Established settlements and the creation of communication networks reduce the possibility of large-scale emergency evacuation and resultant creation of refugee camps, social dislocation, and overall economic burden (Wyett 2013). Additionally, planned migration will reduce population pressure and strain on natural resources, effectively prolonging the inhabitation of the country (Black et al 2011). Relocation as an adaptive response is gaining attention however, the available literature outlining interdisciplinary policy required for preparing for organized relocation is limited (Wyett 2013). Most CIM will be internal with very little international migration, as many will migrate to local urban centers to replace livelihoods lost to climate change impacts, such as drought, flooding, or regional land disputes. However, it is expected that absent of adaptive interventions, pressure on local urban centers will exacerbate, international migration will expand and with it the possibility of insecurity (Fiddian-Qasmiyah et al 2014; Rauveny 2007).

Furthermore, it is significant to consider remaining behind as adaptation to encourage resiliency strategies that prevent large-scale CIM. For those that choose to remain, in many cases, navigation and exploration, thus migration, is a large part of the local cultural heritage (Byravan \& Rajan 2015; Mercer 2010). Many of the communities that will be the most adversely impacted by climate change are those most marginalized, which often includes indigenous populations. While often depicted as vulnerable victims, these communities have adapted to environmental change for generations (Mercer et al 2010). Traditional knowledge is becoming more relevant in the climate adaptation and resiliency discourse by "providing historical baselines, filling observational gaps", and contributing invaluable insights towards effective solutions catered to local communities and cultures (Herrmann 2017, p.210). There is a need for strengthened pathways of information exchange involving mutual respect for both top-down responses to climate change and indigenous experiences to achieve the most effective policy (Mercer et al 2010). Accomplishing this level of cooperation, which would include many considerations such as extensive relationship-building between the historically marginalized and oppressors, however, is a field requiring further investigation.

Encouraging planned migration as the sole solution to CIM detracts from the need for adaptation opportunities that "allow people to lead the kind of lives they value in the places where they belong" (Mortreux \& Barnett 2009, p.106). For many, their traditional heritage is rooted in their natural landscape and thus consider CIM, even voluntary, a last resort. Some will choose to remain and focus on sustainability measures for long-term resilience, rather than migrate as the only route of adaptation (Mortreux \& Barnett 2009). This may include relocating to less vulnerable areas of the island to minimize impacts to the ecosystem that amplify the adverse effects of climate 
change, or innovating rainwater catchment mechanisms to increase freshwater security (Byravan \& Rajan 2015; Farbotko \& Lazrus 2012). Increased awareness of alternative adaptive solutions that will prevent large-scale migration instead of encourage it must be included in future research. Recognizing the importance of migration in the context of adaptation is crucial in determining policies for identifying and protecting climate migrants.

There is a growing concern that people displaced by environmental change pose a security threat. Resources for political refugees are strained, and there is resistance to expanding the pool to include climate refugees, which challenges policymaking.

\section{Climate Securitization}

This section will evaluate the debate regarding the conceptualization of climate change-induced migration as a security threat. It will introduce the various perceptions in the securitization discourse, and examine them in the context of the wider literature to illustrate the implications for CIM recognition in policy.

In the overarching discussion of climate securitization, there are positive and negative perceptions that subsequently influence policy. Boas (2017) outlines four main securitization schools that address the negative perceptions of security, including the traditional view of isolationist policy and fear tactics drawing on national unease for what is "other" in the face of migration. It also addresses the positive outlooks that consider the value of risk perception and seeking opportunities for cooperation, such as engaging in knowledge exchange with vulnerable populations (Boas 2017). Depending on situational context, such as a history of isolationism or collaboration, negative and positive perceptions respectively are integrated into policy. However, securitization should be understood as a rational and interactive process that emphasizes a level of cooperation between the policymakers and audience to develop the optimal policy intervention (Boas 2017). If approached rationally, CIM can provide development opportunities and even contribute to climate mitigation.

Despite scholars indicating the benefits of coordinated strategies, most securitization policy reflects the negative perceptions (Boas 2017; Hartmann 2010). It can be argued that climate change was framed as a security issue simply as an attempt to attract the attention of a wider political audience, especially by the US and Western Europe (The CNA Corporation 2007; European Commission 2013). While climate change did enter the international security discussion, it had a counteractive effect of restricting movements of people fleeing vulnerable regions, and cast affected populations as national security threats (Lister 2014). Border controls restricted climate refugees and the fear tactics employed became legitimized as a response to address the impact of climate change (Lister 2014). The securitization of climate change casts a negative light on CIM and thus prevents any practical policy to address CIM and the potential benefits, such as inducing economic prosperity through an increase in labor force or the integration of innovations only migrants could contribute (Betts et al 2016; Mercer 2010).

It is crucial when addressing CIM to understand the significance of context. Discussions surrounding climate security should include conflict resolution principles and cooperation to achieve political, economic, and social benefits for all. Instead, discussions are focused on Western self-interest and notions of security rooted in xenophobia and the "dangerous poor" (Farbotko \& Lazrus 2012, p.385). Perhaps inadvertently, securitization is drawn to an us/them dichotomy that has been inherent in the relationship between the Global North and the Global South for generations. Western governments influence the narrative by drawing attention to the potential threats of protecting and accepting refugees. By framing CIM in this way, Western governments have in essence diminished the importance of recognizing refugees. Consequently, current policy has created reinforcing feedback loops that restrict movement from vulnerable areas to "safer" areas due to fear of disturbance and conflict. Refugee camps become larger, vulnerable populations swell, resources become strained, rights and needs are restricted, and the possibility of destabilization and violence ensues.

Will climate change result in violent conflict? This is a legitimate question. Climate change itself does not result in violence, but it has the power to amplify pre-existing conditions that create divisions in society, such as inequality and political instability, which become indirect drivers of climate migration (Fornale \& Doebbler 2017). Often, it is the abundance of resources that lead to conflict over inequality and subsequent migration, as opposed to resource scarcity, which, under the right circumstances of adaptation, encourages sustainability and cooperation (Hartmann 2010). Nevertheless, in the wider CIM discourse, refugees are perceived as a security threat despite the conflicting evidence of association and variability of stressors depending on socio-political and economic context. Hsiang \& Burke (2012) reviewed the relationship between climate change and conflict outcomes, and found support for a causal relationship. Another analysis by Buhaug \& Theisen (2012) focused on empirical evidence indicating a broad relationship between environmental insecurity - and its consequences, including displacement- and conflict, but determined that no robust association could be found. Both studies conclude that while there is broad evidence indicating that environmental stress can incite conflict, it is infeasible to attempt to generalize the results 
as each incidence of conflict is context-specific and cannot be applied on a global scale (Hsiang \& Burke 2012; Buhaug \& Theisen 2012). The irrational fear of migrants only prevents effective policy and reinforces negative perceptions and the possibility of conflict. Governments would be remiss in ignoring the benefits of international cooperation to solve the global politics and security challenges associated with climate-induced migration. Securitization by itself is "simply counterproductive" (White 2011, p.9).

\section{Discussing Policy Avenues}

Cooperation as a means to address CIM was identified as a guiding principle in policy implementation. The following examines existing policy recommendations by leading scholars to integrate the importance of international engagement and identifying the beneficial opportunities associated with recognizing climate refugees to create effective policy.

The aforementioned securitization narrative is sustained by security giants, particularly in the West, because they act under the assumption it is in their national self-interest to maintain their current status quo, thus perceiving refugees as disruptive (Levy \& Patz 2015). There is a growing body of scholarship, however, that argues it is in a state's self-interest, economically and politically, to engage in cooperation strategies as a method of sustainable, long-term security (White 2011; Betts et al 2016).

There is a significant lack of economist-led research regarding the interaction between refugees and markets. However, Betts et al (2016) describe what is possible when refugees are given economic freedoms. In Uganda, refugees are provided the right to work and a freedom of intrastate mobility, in a program called the "Self-Reliance Strategy" (Betts et al 2016). The study refutes the assumption that refugees present a significant economic burden as they reintegrate into society. Betts et al (2016) argue that if given the right opportunities to interact with local markets, refugees will "engage in successful reintegration and benefit the larger economy" (p.204). The "right" opportunities could include lowering regulatory barriers to refugees participating in formal markets, greater access to education, and increased access to start-up capital for business development, all to decrease dependency on the state (Betts et al 2016). Much of the existing literature notes that if opportunities instead of restrictions are provided, refugees are capable of contributing to and benefiting the local economies (Ahmed 2018; Fornale \& Doebbler 2017). Unfortunately, Uganda's Self-Reliance Strategy is a unique success (Betts et al 2016). Since the existing literature points to potential conflict and financial burden, many countries continue to be wary of immigrants and will strengthen border controls instead (White 2011). If presented the appropriate opportunities to engage in markets, refugees are capable of integrating into a new society successfully and can provide different perspectives on development. Integration of new perspectives only migrants can provide will immensely benefit the local economies as they offer knowledge, skills, and transnational networks that otherwise would not exist within that community, effectively reshaping that society into one more globalized (Betts et al 2016). The benefits of cultural conversion are widely explored in environmental economics, however further research connecting it and climate-induced migration is recommended.

There is discussion in the South Pacific of preparing its citizens for planned relocation by providing them with skills necessary and access to online education, to promote resettlement (Farbotko \& Lazrus 2012). If other countries were to undertake the Ugandan outlook on refugee assistance as well as recognize that migrants prefer to "migrate with dignity", potential host countries would not be so reluctant to allocate visas to migrants (Farbotko \& Lazrus 2012). Through cooperative efforts, the possibility of dependency is marginally reduced. Supporting refugees' capacities rather than focusing on their vulnerabilities offers an "opportunity to rethink assistance in ways that are more sustainable for refugees, host states"-in terms of long-term economic benefit - and their home countries - in terms of preservation (Betts et al 2016, p.212).

By providing climate refugees with these opportunities, developed nations assume ownership and responsibility to some extent for climate change and CIM (Byravan \& Rajan 2015). It is argued that wealthy countries have an obligation to poor countries as a consequence of the "cumulative burden" of climate change (Byravan \& Rajan 2015). Some studies quantitatively analyze annual greenhouse gas emissions and assign a percentage of the cost to specific countries (Ahmed 2018). Aforementioned, those who will engage in CIM do so due to lack of adaptive capacity, such as loss of livelihood or access to resources, which indicates that most migration will not be long-distance as it requires a level of economic capital many do not possess (Jerneck \& Olsson 2010). Therefore, the majority of migration will occur internally, with the exception of SIDS, with relatively few refugees crossing international borders. The European Commission (2013) specifically suggested a burden-sharing mechanism wherein member-states provide financial assistance for development, humanitarian aid, and resettlement. Though funding is limited, the overarching idea is that to address the CIM that will occur regardless of climate mitigation efforts, a certain level of burden-sharing on an international scale is crucial (European Commission 2013). It is 
acknowledged that voluntary migration strategies can alleviate pressure on resources, circulate innovative resiliency strategies through cultural integration, and revitalize climate mitigation efforts through collaboration (Stapleton et al 2017).

Critical engagement of the international community in cooperation efforts through burden-sharing or wide-spread self-reliance strategies encourage policies to recognize, and in effect protect, climate refugees. Early planning and action to address impacts caused by climate change - to manage CIM - is the most optimal policy option. The early support for climate refugees may not only attenuate human suffering, it would act as an investment in positive global security by preventing violent conflict and catastrophic climate change through pursuing cooperation (Biermann \& Boas 2012, p.83). As for identification, some suggest broadening the Geneva Convention to include climate refugees, despite the limited resources available (Levy \& Patz 2015; Berchin et al 2017). Others indicate the need for an independent protocol amended to existing climate agreements that specifically outline protections and rights for climate refugees in any scenario, via direct or indirect causes, voluntary or involuntary (Biermann \& Boas 2012; Herrmann 2017). By analyzing current scholarship, international cooperation evident in CIM policy will be the best-practice in ensuring sustainable security as it will lessen the incidence and further possibility of violent conflict, as well as contribute to widespread climate mitigation. It will not only address the multifaceted issue of mass migration as a result of climate change, but it will also ensure a more cohesive future built on shared knowledge and resiliency strategies. Essentially, establishing a framework for international engagement to avoid the potential for mass destabilization of populations as a result of climate change should be a priority.

\section{Conclusions}

Understanding the challenges and opportunities associated with recognizing climate refugees is a key step toward rational policy. Whether they are referred to as refugees or migrants, policies must protect and provide for them as a core value of society. Alongside the challenges of reintegration into a new community - which are lessened the more protections exist - there are opportunities that appear when freedoms are presented to the migrants themselves. The first integral step towards developing policy is a formal process to define and agree upon universal recognition of climate refugees, a cause that is proposed in much of the literature but it is not widely discussed on how precisely to achieve it.

Climate-induced migration scholarship is a burgeoning field that involves many interrelated intricacies that often lack quantitative data and evidence to support many of the generalizations disseminated in this subject. Future research is needed to adequately characterize the climate change-induced migration continuum and to begin to devise policy options. It is clear that CIM is a complex synthesis of environment, economics, and human behavior. Due to the limited scope of this paper, specific connections and case studies could not be singled out primarily due to the inability to generalize policy avenues. This is recognized to be a significant limitation of this paper, as there are many interesting routes and scenarios that require future exploration. These include the health consequences leading to migration, such as significant environmental degradation and the health risks associated with dense urban centers; psychological traumas associated with losing one's homeland to climate impacts; the specific implications for women and children; and the interactions with human rights policy in the larger CIM conversation.

Additionally, this review maintained the typical Global North/ Global South dichotomy in this discourse. However, as has been noted throughout, contextualization is significant in this research field, thus this dichotomy does not always apply to every CIM conversation. A policy that is effective in one scenario may not be the best practice in another region with different cultural values and politics. Thus, it is crucial that further cooperative conversations involve not just the overarching idea of sustainability but local views as well. Ultimately, many of the concerns surrounding CIM can be attributed to the lack of an overarching conceptualization of climate refugees. Thus, recognition is the first crucial step toward addressing climate change-induced migration through international engagement in adaptation and resilience, and to recognize the human rights and needs of populations that will destabilized by climate change. By supporting cooperative strategies and the capacity of climate change-induced migrants, we will effectively be reshaping our world into something new, something better.

\section{References}

Ahmed, B. (2018). Who Takes Responsibility for Climate Refugees? International Journal of Climate Change Strategies and Management, 10(1), 5-26. https://doi.org/10.1108/IJCCSM-10-2016-0149

Ayers, J., Alam, M., \& Huq, S. (2010). Chp.17: Global Adaptation Governance Beyond 2012: Developing Country Perspectives. In Biermann, F, Pattberg, P, \& Zelli, F. (Eds.), Global Climate Governance Beyond 2012 (pp. 270-285). Cambridge University Press. https://doi.org/10.1017/CBO9781139107150.021 
Berchin, II., Valduga, I. B., Garcia, J., \& de Andrade Guerra, J. B. S. O. (2017). Climate Change and Forced Migrations: An Effort Towards Recognizing Climate Refugees. Geoforum, 84(1), 147-150. https://doi.org/10.1016/j.geoforum.2017.06.022

Betts, A., Bloom, L., Kaplan, L., \& Omata, N. (2016). Refugee Economies: Forced Displacement and Development. Oxford University Press. https://doi.org/10.1093/acprof:oso/9780198795681.001.0001

Biermann, F., \& Boas, I. (2008). Protecting Climate Refugees: The Case for a Global Protocol. Environment: Science and Policy for Sustainable Development, 50(6), 8-17. https://doi.org/10.3200/ENVT.50.3.6-17

Biermann, F., \& Boas, I. (2010). Chp.16: Global Adaptation Governance: the Case of Protecting Climate Refugees. In Biermann, F., Pattberg, P., \& Zelli, F. (Eds.), Global Climate Governance Beyond 2012 (pp.255-269). Cambridge University Press. https://doi.org/10.1017/CBO9781139107150.020

Biermann, F., \& Boas, I. (2012). Climate Change and Human Migration: Towards a Global Governance System to Protect Climate Refugees. In Scheffran, J et al. (Eds.), Climate Change, Security, and Human Conflict (pp. 291-300). Springer. https://doi.org/10.1007/978-3-642-28626-1_15

Black, R., Adger, W. N., Arnell, N. W., Dercon, S., Geddes, A., \& Thomas, D. S. G. (2011). The Effect of Environmental Change on Human Migration. Global Environmental Change, 21S(1), S3-S11. https://doi.org/10.1016/j.gloenvcha.2011.10.001

Black, R., Bennett, S. R. G., Thomas, S. M., \& Beddington, J. R. (2011). Migration as Adaptation. Nature, 478(1), 447-450. https://doi.org/10.1038/478477a

Boas, I. (2017). Climate Migration and Security. Routledge Research in Environmental Politics.

Buhaug, H., \& Theisen, O. M. (2012). On Environmental Change and Armed Conflict. In Scheffran, J. et al. (Eds.), Climate Change, Security, and Human Conflict (pp. 43-56). Springer. https://doi.org/10.1007/978-3-642-28626-1_2

Byravan, S., \& Rajan, S. C. (2015). Sea Level Rise and Climate Change Exiles: A Possible Solution. Bulletin of Atomic Scientists, 71(2), 21-28. https://doi.org/10.1177/0096340215571904

European Commission. (2013). Climate Change, Environmental Degradation, and Migration: A EU Strategy on Adaptation to Climate Change. Communication from the Commission to the European Parliament, the Council, the Economic and Social Committee and the Committee of the Regions. pp.1-36.

Farbotko, C., \& Lazrus, H. (2012). The First Climate Refugees? Contesting Global Narratives of Climate Change in Tuvalu. Global Environmental Change, 22(1), 382-390. https://doi.org/10.1016/j.gloenvcha.2011.11.014

Fiddian-Qasmiyah, E., Loescher, G., Long, K., \& Sigona, N. (2014). The Oxford Handbook of Refugee and Forced Migration Studies. Oxford University Press. https://doi.org/10.1093/oxfordhb/9780199652433.001.0001

Fornale, E., \& Doebbler, C. F. J. (2017). UNHCR and Protection and Assistance for Victims for the Climate Change. The Geographical Journal,183(4), 329-335. https://doi.org/10.1111/geoj.12193

Hartmann, B. (2010). Rethinking Climate Refugees and Climate Conflict: Rhetoric, Reality, and the Politics of Policy Discourse. Journal of International Development, 22(1), 233-246. https://doi.org/10.1002/jid.1676

Herrmann, V. (2017). America's First Climate Change Refugees: Victimization, Distancing, and Disempowerment in Journalistic Storytelling. Energy Research and Social Science, 31(1), 205-214. https://doi.org/10.1016/j.erss.2017.05.033

Hsiang, S. M., \& Burke, M. (2012). Climate, Conflict, and Social Stability: What Does the Evidence Say? Climatic Change, 123(1), 39-55. https://doi.org/10.1007/s10584-013-0868-3

Intergovernmental Panel on Climate Change. (2014). Fifth Assessment Report: Climate Change 2014, Synthesis Report. United Nations.

Jerneck, A., \& Olsson, L. (2010). Chp.18: Shaping Future Adaptation Governance: Perspectives from the Poorest of the Poor. In Biermann, F., Pattberg, P., \& Zelli, F. (Eds.), Global Climate Governance Beyond 2012 (pp.286-305). Cambridge University Press. https://doi.org/10.1017/CBO9781139107150.022

Levy, B. S., \& Patz, J. A. (2015). Climate Change, Human Rights, and Social Justice. Annals of Global Health, 81(3), 310-322. https://doi.org/10.1016/j.aogh.2015.08.008

Lister, M. (2014). Climate Change Refugees. Critical Review of International Social and Political Philosophy, 17(5), 618-634. https://doi.org/10.1080/13698230.2014.919059 
Mercer, J. (2010). Disaster Risk Reduction or Climate Change Adaptation: Are We Reinventing the Wheel? Journal of International Development, 22(1), 247-264. https://doi.org/10.1002/jid.1677

Mercer, J., Kelman, I., Taranis, L., \& Suchet-Pearson, S. (2010). Framework for Integrating Indigenous and Scientific Knowledge for Disaster Risk Reduction. Disasters, 34(1), 214-239. https://doi.org/10.1111/j.1467-7717.2009.01126.x

Mortreux, C., \& Barnett, J. (2009). Climate Change, Migration, and Adaptation in Funafuti, Tuvalu. Global Environmental Change, 19(1), 105-112. https://doi.org/10.1016/j.gloenvcha.2008.09.006

Patz, J. A., Grabow, M. L., \& Limaye, V. S. (2014). When It Rains, It Pours: Future Climate Extremes and Health. Annals of Global Health, 80(1), 332-344. https://doi.org/10.1016/j.aogh.2014.09.007

Rauveny, R. (2007). Climate Change-Induced Migration and Violent Conflict. Political Geography, 26(1), 656-673. https://doi.org/10.1016/j.polgeo.2007.05.001

Srikanth, D. (2014). Non-Traditional Security Threats in the 21st Century: A Review. International Journal of Development and Conflict, 4(1), 60-68.

Stapleton, S. O., Nadin, R., Watson, C., \& Kellett, J. (2017). Climate Change, Migration, and Displacement: The Need for a Risk-Informed and Coherent Approach. United Nations Development Programme. Pp.1-36.

The CNA Corporation. (2007). National Security and the Threat of Climate Change. The Military Advisory Board, The CNA Corporation, United States.

Thomalla, F., Downing, T., Spanger-Siegfried, E., Han, G., \& Rockstrom, J. (2006). Reducing Hazard Vulnerability: Towards a Common Approach Between Disaster Risk Reduction and Climate Adaptation. Disasters, 30(1), 39-48. https://doi.org/10.1111/j.1467-9523.2006.00305.x

Tyler, S., \& Moench, M. (2012). A Framework for Urban Climate Resilience. Climate and Development, 4(4), 311-326. https://doi.org/10.1080/17565529.2012.745389

White, G. (2011). Climate Change and Migration: Security and Borders in a Warming World. Oxford University Press. https://doi.org/10.1093/acprof:oso/9780199794829.001.0001

Wyett, K. (2013). Escaping the Rising Tide: Sea Level Rise and Migration in Kiribati. Asia and Pacific Policy Studies, 1(1), 171-185. https://doi.org/10.1002/app5.7

Zetter, R. (2011). Environmentally Displaced People: Informing Policy Regarding a New Category of Involuntary Migrants. Refugee Studies Centre, University of Oxford.

\section{Copyrights}

Copyright for this article is retained by the author(s), with first publication rights granted to the journal.

This is an open-access article distributed under the terms and conditions of the Creative Commons Attribution license (http://creativecommons.org/licenses/by/4.0/). 